\title{
Coulisses
}

Revue de théâtre

13 | Hiver 1996

Varia

\section{Instantané sur la diffusion culturelle du théâtre, des partenaires et des films}

Jacques Materne

\section{OpenEdition}

1 Journals

Édition électronique

URL : http://journals.openedition.org/coulisses/4215

DOI : $10.4000 /$ coulisses.4215

ISSN : 2546-9460

Éditeur

Presses universitaires de Franche-Comté

\section{Édition imprimée}

Date de publication : 1 janvier 1996

Pagination : 60-61

ISSN : 1150-594X

\section{Référence électronique}

Jacques Materne, «Instantané sur la diffusion culturelle du théâtre, des partenaires et des films »,

Coulisses [En ligne], 13 | Hiver 1996, mis en ligne le 15 mars 2019, consulté le 08 octobre 2020. URL:

http://journals.openedition.org/coulisses/4215; DOI : https://doi.org/10.4000/coulisses.4215

Ce document a été généré automatiquement le 8 octobre 2020.

Coulisses 


\section{Instantané sur la diffusion culturelle du théâtre, des partenaires et des films}

Jacques Materne

\section{Cinéma Kursaal}

1 Le cinéma Kursaal, salle d'art et essai commerciale, collabore souvent avec les différents partenaires culturels de Besançon (Musées, CCPPO, Acte, Université, Espace Scène nationale, Cinémas Plazza, etc.). C'est pourquoi il était tout naturel de le faire avec l'opéra théâtre sur les opéras de Brecht. De plus il s'agissait de participer au projet de deux amis de longue date, Didier Brunel et Charlotte Nessi avec qui j'avais déjà monté un opéra jazz (Jazz en Franche-Comté 1989).

C'est dans le cadre des célébrations du centenaire de l'invention du cinéma par les frères Lumière, que le cinéma Kursaal a donc participé avec l'opéra théâtre à la redécouverte d'un patrimoine culturel nécessaire à la compréhension de tout art du XX ème siècle. Il s'agit des années de l'entre-deux guerres durant lesquelles la définition d'un nouveau langage cinématographique, l'expressionnisme, en tant qu'expression artistique et vecteur d'un discours, a conduit nombre de musiciens et d'artistes à redéfinir complètement leur langage. L'expressionnisme qui a touché tous les arts s'observe à partir de 1925 dans le cinéma. C'est un mouvement de révolte, contre l'étouffement de la société prussienne caporaliste et bureaucratique, contre l'humiliation de la défaite. Prenant conscience de sa solitude, l'Homme pousse un cri : ce cri c'est l'expressionnisme. 


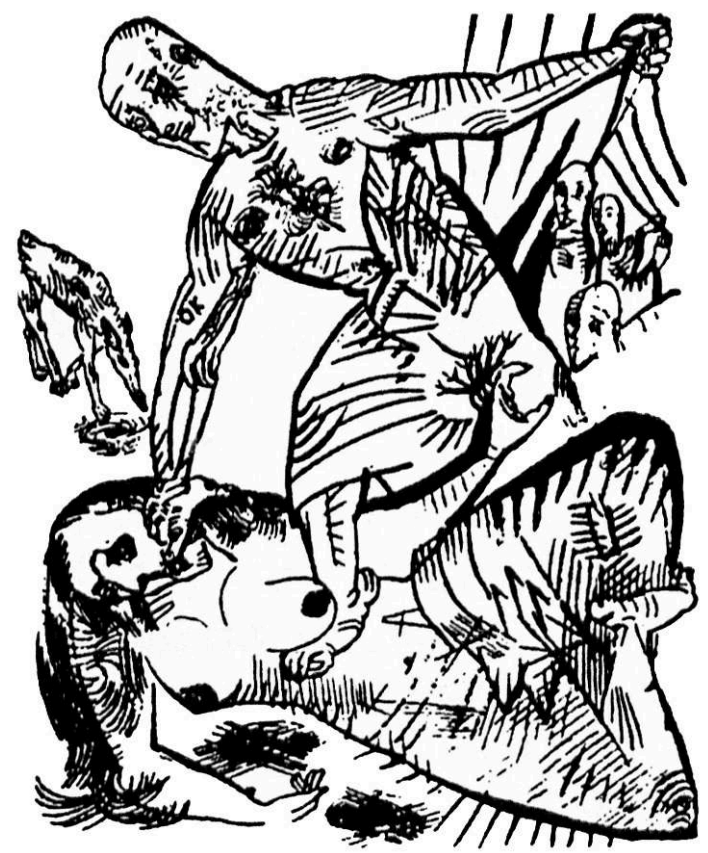

2 Cette forme d'expression refuse l'impressionnisme, le réalisme et le naturalisme, et l'artiste recherche «l'expression la plus expressive » (Kasimir Edschmid). L'esthétique expressionniste s'exprime dans trois domaines essentiels : le décor est choisi pour son étrangeté et l'angoisse qu'il suscite, l'éclairage symbolise plastiquement les états d'âme en mettant en scène le conflit de l'ombre et de la lumière, le jeu de l'acteur enfin aide à exprimer un goût profond pour le magique, l'onirique, l'excessif, le démesuré, le démoniaque.

Novembre a été l'occasion d'une nouvelle contribution pour le Kursaal lors de la création de René Loyon: Peep Show dans les Alpes de Markus Köbeli, auteur suisse étonnant qui dénonce la sous culture médiatique en chantant la ruralité helvète. Le samedi 18 novembre à 14 heures le Kursaal a proposé une séance unique du film d'Yves Yersin : Les petites fugues avec Michel Robin. Tous les spectateurs du CDN ont bénéficié d'une entrée gratuite à cette séance.

C'est dans le même esprit et toujours dans le cadre du centenaire du cinéma que nous avons présenté avec l'Opéra Théâtre le 19 Décembre 95 La nouvelle Babylone, grand film du patrimoine soviétique de l'entre-deux guerres de Kozintzev et Travberg. La musique de Dimitri Chostakovitch a été jouée en direct pendant la projection par l'orchestre de Besançon sous la direction de Peter Csaba.

Enfin le cinéma Kursaal est aussi le partenaire de l'Université de Franche-Comté, du CROUS et des associations d'étudiants pour l'organisation de "Ciné Campus", un cinéma sur le campus de la Bouloie, à l'amphi Courbet (entrée $10 \mathrm{~F}$ ). Cette année les étudiants ont choisi la comédie et le rire. La première séance du 14 Décembre 95 (également dans le cadre du centenaire) proposait Steamboat Bill Junior, le film de Buster Keaton, accompagné en jazz et en direct par le trio de Pierre Boespflug; à suivre: Tex Avery et compagnie (le 10/01), Les cadavres ne portent pas de costard (le 
7/02), Les tontons flingueurs (le 13/03), Tombe les filles et tais toi (le 3/04) et Les hommes préfèrent les blondes (le 24/04).

4 Le cinéma Kursaal a bien sûr d'autres projets, et des partenaires pour 96, Raoul Ruiz et Valeria Sarmiento, le cinéma latino-américain avec la fac de lettres, un festival de cinéma japonais avec le CLA et peut-être en 96 Le Cuirassé Potemkine accompagné par les musiciens de jazz de l'ARFI... 